\title{
Whole genome characterization of autochthonous Bos taurus brachyceros and introduced Bos indicus indicus cattle breeds in Cameroon regarding their adaptive phenotypic traits and pathogen resistance
}

\author{
Archile Paguem ${ }^{1,2^{*}}$ (D) Babette Abanda ${ }^{1,2}$, Mbunkah Daniel Achukwi ${ }^{3}$, Praveen Baskaran ${ }^{4}$, Stefan Czemmel ${ }^{4}$,
} Alfons Renz ${ }^{2}$ and Albert Eisenbarth ${ }^{2,5}$

\begin{abstract}
Background: African indigenous taurine cattle display unique adaptive traits shaped by husbandry management, regional climate and exposure to endemic pathogens. They are less productive with respect to milk and meat production which has been associated with amongst others, small size, traditional beliefs, husbandry practices, limited feed resources, disease burden and lack of sustained breeding for trait improvement. This resulted in the severe dwindling of their population size rendering them vulnerable to extinction.

The Namchi taurine cattle breed is referred to as [Namchi (Doayo)] and shows resistance traits against trypanosome infection and exposure to tick infestation. Nonetheless, the historically later introduced Zebu cattle are the main cattle breeds in Africa today, even though they suffer more from locally prevailing pathogens.

By using a whole genome sequencing approach, we sequenced with high depth for the first time the genomes of five cattle breeds from Cameroon in order to provide a valuable genetic resource for future African cattle breeding: the Namchi, an endangered trypano-tolerant taurine breed, the Kapsiki, an indigenous trypano-susceptible taurine breed, and three Zebu (Bos indicus indicus) breeds: Ngaoundere Gudali, White Fulani and Red Fulani.
\end{abstract}

(Continued on next page)

\footnotetext{
* Correspondence: achillepaquem@gmail.com

'Department of Biological Science, Faculty of Science, University of Ngaoundéré, Ngaoundéré, Cameroon

Department of Comparative Zoology, Institute for Evolution and Ecology, University of Tübingen, Tübingen, Germany

Full list of author information is available at the end of the article
}

(c) The Author(s). 2020 Open Access This article is licensed under a Creative Commons Attribution 4.0 International License, which permits use, sharing, adaptation, distribution and reproduction in any medium or format, as long as you give appropriate credit to the original author(s) and the source, provide a link to the Creative Commons licence, and indicate if changes were made. The images or other third party material in this article are included in the article's Creative Commons licence, unless indicated otherwise in a credit line to the material. If material is not included in the article's Creative Commons licence and your intended use is not permitted by statutory regulation or exceeds the permitted use, you will need to obtain permission directly from the copyright holder. To view a copy of this licence, visit http://creativecommons.org/licenses/by/4.0/. The Creative Commons Public Domain Dedication waiver (http://creativecommons.org/publicdomain/zero/1.0/) applies to the data made available in this article, unless otherwise stated in a credit line to the data. 
(Continued from previous page)

Results: Approximately 167 Gigabases of raw sequencing data were generated for each breed and mapped to the cattle reference genomes ARS-UCD1.2 and UMD3.1.The coverage was 103 to 140-fold when aligning the reads to ARS-UCD1.2 with an average mapping rate of 99\%, and 22 to 30-fold when aligning the reads to UMD3.1 with an average mapping rate of $\sim 64 \%$. The single nucleotide polymorphisms (SNPS) obtained from analysis using the genome ARS-UCD1.2 were compared with reference genomes of European Bos taurus Holstein, the Asian Bos indicus Brahman, and the African trypanotolerant N'Dama breeds.

A total of 100 million (M) SNPs were identified and 7.7 M of those were breed-specific. An approximately 11.1 M constituted of small insertions and deletions. By using only breed-specific non-synonymous variants we identified genes as genetic signatures and associated Gene Ontology (GO) terms that could explain certain cattle-breed specific phenotypes such as increased tolerance against trypanosome parasites in the Namchi breed and heat tolerance in the Kapsiki breed. Phylogenetic analysis grouped, except for Namchi, the Bos taurus breeds Kapsiki, N'Dama and Holstein together while the B. indicus breeds White and Red Fulani, Gudali and Brahman clustered separately. The deviating result for Namchi indicates a hybrid status of the selected animal with a recent introgression of Zebu genes into its genome.

Conclusions: The findings provide the first comprehensive set of genome-wide variant data of the most important Cameroonian cattle breeds. The genomic data shall constitute a foundation for breed amelioration whilst exploiting the heritable traits and support conservation efforts for the endangered local cattle breeds.

Keywords: Whole genome sequencing, Trypanotolerance, Bos taurus: Namchi, Kapsiki, Bos indicus: white Fulani, Red Fulani, Gudali, Cameroon

\section{Background}

More than 150 cattle breeds or distinct populations have been recorded in Africa [1, 2]. Their phenotypes cluster into the humpless taurine, the humped Zebu, and the anciently fixed taurine-Zebu crossbreeds known as Sanga in East Africa [3].

In Sub-Saharan Africa, trypanosomiasis (Nagana), dermatophilosis, tick-borne diseases and gastrointestinal helminthiasis are the major endemic diseases affecting cattle productivity [4, 5]. Indigenous local taurine breeds like Doayo (also known under the Fulani word Namchi) are more resistant or tolerant to most endemic diseases than Zebu cattle [5]. They originated from ancestral aurochs populations Bos primigenius primigenius and B. primigenius opisthonomus from two centers of domestication, namely the Middle East and North Africa, respectively [6, 7].

Today Namchi and Kapsiki are geographically restricted to endemic areas of human and animal trypanosomiasis in Northern Cameroon. Whereas N'dama and Kuri cattle are grouped as residual longhorn Bos taurus longifrons introduced already 10,000 years ago [5, 8], Baoulé, Namchi and Kapsiki belong to the West African Shorthorn (WAS) Bos taurus brachyceros domesticated on the continent some 6500 years ago $[6,7]$.

The Kapsiki cattle form a population of approximately 5000 animals that are found mainly in the Mayo Tsanaga (Rhumsiki) area of the Far North region [9]. In contrast, the Namchi cattle have a population size of only 1000 to 2000 heads in the Poli mountains, which are up to $1900 \mathrm{~m}$ above sea level- and surround savannah lowlands in the Faro division of Cameroon's
North region $[8,10]$. The breed is well adapted to the local environment, including endemic parasites like trypanosomes and ticks [8, 11], but of small size and weight, thus economically not interesting for milk and meat production. The usually small herd size of 5 to 50 animals are kept semi-wild, and are neither milked nor exploited commercially. They rather play an important role in the traditional culture of local tribes, like dowries, special feasts and rituals. During the last three decades, uncontrolled crossbreeding with Zebu cattle have severely dwindled the gene pool of this taurine cattle population [8]. In 1992, these breeds have been classified by the Food and Agricultural Organization (FAO) as being at risk of becoming extinct [10], hence the conservation of their genetic resources has been highly prioritized. Unfortunately, the majority of the planned strategies for their conservation has not been adopted in the field. The continuous influx of Zebu genes into the WAS breeds threatens the innate characteristics of trypanotolerance and other disease resistances [3].

Bos indicus Zebu cattle in Africa fall into two distinct groups, the West African Zebu (WAZ) and East African Zebu (EAZ). In Cameroon, 99\% of the estimated population of six million cattle are WAZ breeds. They consist of two major sub-types of the Sokoto and Adamawa Gudali [12]. In Central Africa, they have the highest potential for beef and dairy production in comparison to other regional WAZ breeds, like White Fulani and Red Fulani. These Fulani cattle are long-horned and longlegged Zebu cattle and are mainly kept by the nomadic Bororo people [13]. All Zebu breeds were introduced 
through the Nile-valley and the Horn of Africa around 2000 years ago. They started to become more widespread about 700 years ago with hamitic migrations in North and East Africa [7, 14] and throughout the Sahel zone south of the Sahara. They arrived in Northern Cameroon, coming from the Bornu (Nigeria today) some 200 years ago. This relatively short time span for evolutionary adaption is reflected by a higher susceptibility to locally endemic diseases and disease vectors making reliance on veterinary drug interventions essential for their survival.

Better knowledge of unique adaptive traits against locally prevailing pathogens is needed not only for breed conservation, but also for future genetic amelioration of cattle breeds to mitigate food insecurity problems in Africa. Long-term selection pressure has operated on the genomic architecture and on regions that control traits for adaptive fitness [1]. For example, autosomal and Ychromosomal microsatellites indicate a high level of genetic diversity in African cattle breeds as a consequence of repetitive introgression of Zebu genes into autochthonous taurine genome across the continent [1-8]. Genome research initiatives, like Bovine Genome Sequencing, HapMap and 1000 Bulls have fostered our understanding of bovine evolution and the complex formation of genetic variants [15-17]. The free availability of cattle reference genomes facilitates whole genome re-sequencing approaches, which are steadily expanding [15-17].

In this study, we characterize for the first time the complete genomes of five cattle breeds in Cameroon, namely the endangered taurine trypanotolerant Namchi, the trypano-susceptible Kapsiki taurine, and the three Zebu breeds Gudali, White Fulani and Red Fulani, which are all trypano-susceptible. Using the genomic data, $\sim 100$ million (M) SNPs were identified in this study of which $7.7 \mathrm{M}(\sim 8 \%)$ were considered as novel variants. In general, lower genetic diversity was found in African taurine cattle breeds than in the Cameroonian Bos indicus breeds. Furthermore, breed-specific non-synonymous variants were detected, which can be linked to important traits such as trypanotolerance in Namchi and heat tolerance in Kapsiki.

\section{Results and discussion}

\section{Whole genome sequencing analysis}

Genomic DNA from the cattle breeds Gudali, White Fulani, Red Fulani, Namchi and Kapsiki were sequenced (150-bp paired-end reads) with the Illumina HiSeq4000 sequencing platform and libraries were sequenced using 150-bp paired-end reads. This generated a total of $\sim 840$ Gb of raw reads for all five breed samples analyzed together, averaging to $\sim 167 \mathrm{~Gb}$ per sample which provides, to the best of our knowledge, the first comprehensive set of high depth, whole genome variant data of these breeds.
The chosen approach of high depth sequencing yielded approximately $10^{9}$ reads per sample (Tables 1 \& 2 ) which allowed us to obtain a high coverage per animal tested. However, it also resulted in a relatively low mapping rate for the African cattle breeds ranging from 63 to $65 \%$ when aligned to the reference genome UMD3.1 (Table 1). This low mapping rate could be explained by 1) the PCR-free preparation of sequencing libraries, which implies that bovine DNA and non-bovine DNA such as blood microbes and parasites could have been sequenced at similar rates, or 2) the reference genome is incomplete, or 3) the African cattle breed samples chosen are evolutionarily more distant compared to the reference genome and therefore contain sequences of genomic regions not present in the UMD3.1 cattle reference genome. In order to better understand this, unmapped reads were assembled into contigs using the de novo sequence assembler ABySS and compared against the NCBI Blastn database [Fig. 1, Additional file 1 Table S1]. The results obtained from this analysis did not support the hypothesis of microbial or parasitic DNA contamination. Species such as Trichogramma pretiosum in the Brahman control sample, the bacteria Lelliottianimi pressuralis and Enterobacter spp. in White Fulani, Babesia spp. and Theileria spp. cosmopolitan blood parasites of ruminants which are known to inflict diseases were detected in Namchi, but only supported by a very low number of Blastn alignments [Additional file 1 Table S1]. Still, the presence of such organisms in our samples is in line with a recent epizootiological survey in the same indigenous Cameroonian cattle breeds that revealed nearly $90 \%$ of animals carried tick-borne bacterial, piroplasmid and protozoan pathogens $[18,19]$.

Rather, the mapping results indicated that the analyzed breeds are evolutionary more distant compared to the reference genome UMD3.1, or that this genome is not complete. This assumption is supported that Bos mutus was the best scoring result in $65 \%$ of the Blastn alignments with a mean sequence identity of $98 \%$ across all samples, indicating that most unmapped read contigs were of Bovidae origin, but have not been found in the reference genome UMD3.1. In contrast, Bos taurus and Bos indicus reads were only found in $\sim 3 \%$ and $~ 1 \%$ of the Blastn hits, respectively, demonstrating that most of the reads originating from those species were correctly mapped. There were no obvious differences in Blastn results when comparing African Zebu cattle with Namchi and Kapsiki [Fig. 1, Additional file 1 Table S1], although it seems conceivable to expect Namchi and Kapsiki taurine breeds rather distinct from the reference genome in comparison to the Zebu cattle. The recently published reference genome assembly ARS-UCD 1.2 (NCBI RefSeq accession GCF_002263795.1), based on the same original animal (Hereford breed UMD3.1) was created by 
Table 1 Summary of sequencing results of the genomes of five Cameroonian cattle breeds including the number of total reads and variants called in million $(M)$ reads

\begin{tabular}{|c|c|c|c|c|c|c|c|c|c|c|}
\hline Breeds & Mapped Reads & Total Reads & Mapping rate (\%) & Coverage [x] & SNPS & Indels & Bs- SNPs & Hom & Het & Het/ Hom \\
\hline Namchi & 596.3 & 935.3 & 63.7 & 22.8 & 6.31 & 0.53 & 0.40 & 2.51 & 3.80 & 1.5 \\
\hline Kapsiki & 743.7 & 1160.6 & 64.1 & 28.6 & 5.40 & 0.47 & 0.37 & 1.55 & 3.85 & 2.5 \\
\hline W. Fulani & 707.6 & 1103.1 & 64.1 & 27.2 & 6.42 & 0.55 & 0.42 & 2.29 & 4.13 & 1.8 \\
\hline R. Fulani & 716.3 & 1102.2 & 65.0 & 27.6 & 6.70 & 0.57 & 0.47 & 2.15 & 4.55 & 2.1 \\
\hline Gudali & 804.9 & 1271.1 & 63.3 & 30.8 & 6.65 & 0.57 & 0.46 & 2.17 & 4.49 & 2.1 \\
\hline N'Dama & 154.5 & 282.1 & 54.8 & 4.7 & 4.26 & 0.35 & 0.22 & 1.53 & 2.73 & 1.8 \\
\hline Brahman & 146.4 & 177.0 & 82.7 & 5.1 & 7.31 & 0.60 & 0.76 & 2.96 & 4.36 & 1.5 \\
\hline Holstein & 255.7 & 460.6 & 55.5 & 7.6 & 3.05 & 0.26 & 0.33 & 1.19 & 1.87 & 1.6 \\
\hline
\end{tabular}

The reference genome breed was Hereford (UMD3.1). Whole genome data of the breeds N'Dama, Brahman and Holstein were retrieved from the NCBI archive SRA [Holstein (SRR934414), N'Dama (SRR3693376) and Brahman (SRR6649996)]. Hom = homozygous, Het = heterozygous, Het/ Hom = heterozygous to homozygousratio, W. Fulani = White Fulani; R. Fulani = Red Fulani. Bs-SNPs = breeds specific SNPs

applying a combination of long and short reads for a de novo assembly strategy, and showed a $>200$-fold improvement in continuity, as well as 10 -fold improvement in accuracy and completeness than the previous cattle reference genome [20]. Therefore, this optimized genome was also used as reference to map the reads of the Cameroonian cattle breeds. Interestingly, a very high proportion of raw reads was mapped ranging from 98.9\% for Namchi up to $99.6 \%$ for Red Fulani (Table 2). Our mapping rates were even higher than reported by Kim et al. [17] from other indigenous East African cattle breeds (Ankole, Boran and Ogaden) and of other cattle re-sequencing studies published [16, 17, 21-23]. Further, the depth of coverage, ranging from 103-fold for Bos taurus Namchi to 140-fold for Bos indicus Zebu Gudali is also considerably high in comparison to 10.8- and 15.8-fold coverage obtained by Kim et al. [17] and Kawahara-Miki et al. [21], respectively. Taylor et al. [22] suggested that about $95 \%$ of the total variants within the genome of cattle are discovered at an average sequence depth of 23.3-fold which implies the data obtained in this study is sufficient to detect SNPs and InDels variants with high confidence.

\section{Variant calling results}

A total of $\sim 100$ million (M) SNPs were identified in this study of which $7.7 \mathrm{M}(\sim 8 \%)$ were not found in the 1000 Bulls Genomes Project and considered as novel variants (Table 2; Fig. 2A). On average for each breed, $1.4 \mathrm{M}$ $(12 \%)$ of the detected variants had small insertions and deletions (InDels, Table 2). The SNP variants results from Cameroonian cattle were much higher as compared to the 27 M SNPs obtained by Stafuzza et al. [23] on Bos indicus Gyr, Girolando, Gruzerat and Bos taurus Holstein cattle breeds from Brazil, whereas our obtained SNP variants were markedly lower as compared to those reported by Kim et al. [17] on East African zebu (Boran, Ogaden, Kenana) and Sanga (Ankole, taurine/zebu crossbreeds). The ratio of the number of heterozygous to homozygous SNP variants was different across the cattle breeds. Brahman, Holstein and Namchi had the

Table 2 Summary of sequencing results of the genomes of five Cameroonian cattle breeds including the number of total reads and variants called in million $(M)$ reads

\begin{tabular}{|c|c|c|c|c|c|c|c|c|c|c|}
\hline Breeds & Mapped Reads & Total Reads & Mapping rate (\%) & Coverage $[x]$ & SNPs & Indels & Bs-SNPs & Hom & Het & $\mathrm{Het} / \mathrm{Hom}$ \\
\hline Namchi & 930.8 & 935.3 & 98.9 & 102.8 & 12.74 & 1.51 & 0.91 & 5.54 & 8.10 & 1.5 \\
\hline Kapsiki & 1154.9 & 1160.6 & 99.0 & 127.6 & 10.81 & 1.34 & 0.83 & 3.42 & 8.23 & 2.4 \\
\hline W. Fulani & 1098.0 & 1103.1 & 99.0 & 121.3 & 12.99 & 1.56 & 0.95 & 5.07 & 8.87 & 1.7 \\
\hline R. Fulani & 1098.0 & 1102.2 & 99.1 & 121.3 & 13.54 & 1.62 & 1.05 & 4.73 & 9.86 & 2.1 \\
\hline Gudali & 1267.0 & 1271.1 & 99.1 & 140.0 & 13.37 & 1.62 & 1.09 & 4.77 & 9.70 & 2.0 \\
\hline N'Dama & 271.8 & 282.1 & 99.6 & 30.0 & 8.53 & 1.01 & 0.48 & 3.32 & 5.68 & 1.7 \\
\hline Brahman & 176.9 & 177.0 & 99.4 & 19.5 & 14.21 & 1.73 & 1.70 & 6.53 & 9.38 & 1.4 \\
\hline Holstein & 453.1 & 460.6 & 99.5 & 50.0 & 5.66 & 0.76 & 0.73 & 2.59 & 3.80 & 1.5 \\
\hline
\end{tabular}

The new reference genome breed was Hereford (ARS-UCD1.2). Whole genome data of the breeds N'Dama, Brahman and Holstein were retrieved from the NCBI archive SRA [Holstein (SRR934414), N'Dama (SRR3693376) and Brahman (SRR6649996)]. Hom = homozygous, Het = heterozygous, Het/ Hom = heterozygous to homozygous ratio, W. Fulani $=$ White Fulani; R. Fulani $=$ Red Fulani. Bs-SNPs $=$ breeds specific SNPs 


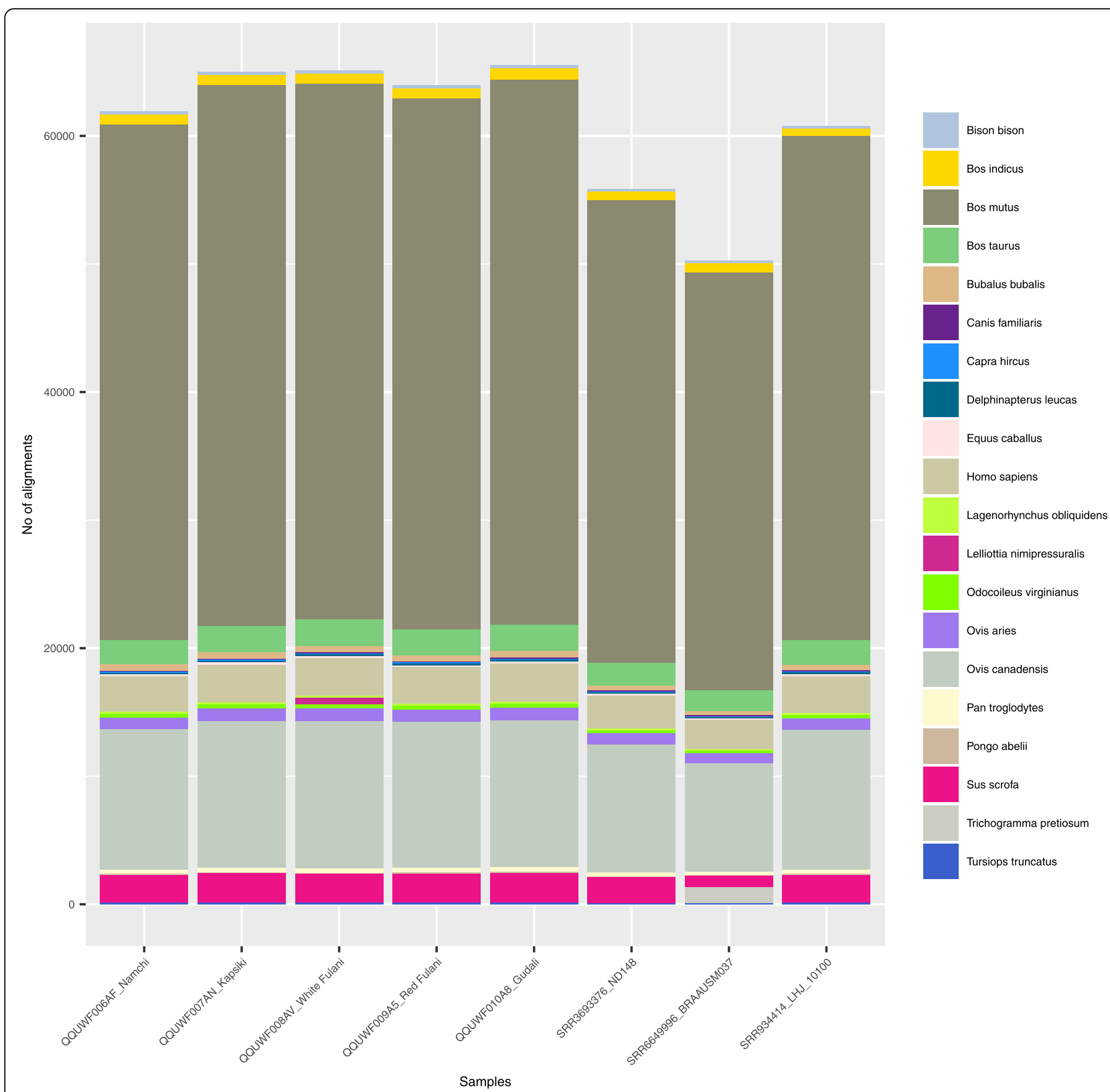

Fig. 1 Pairwise alignment of contigs assembled from unmapped reads to the non-redundant nucleotide database from NCBI. Each bar represents an individual cattle breed and contained the twenty most common species with significant alignments to the de novo assembled contigs

lowest rate, whereas Kapsiki had the highest (Table 2). The low ratio of heterozygous to homozygous SNPs in Brahman and Namchi cattle could mean that they experience admixture, as reported by Freemann et al. [24] in African taurines from Cameroon.

\section{Genetic variability and similarity across breeds}

For downstream analysis of single nucleotide polymorphisms (SNPs) we used the genome ARS-UCD1.2 but not UMD3.1 and compared it with reference genomes of European Bos taurus Holstein, Asian Bos indicus
Brahman and African trypanotolerant N'Dama breeds. A total of 1,649,795 SNPs were common across all breeds, and 302,546 SNPs were Zebu-specific, distributed between Brahman, Red Fulani, White Fulani and Gudali cattle breeds (Fig. 3). More surprisingly, there were 27, 443 SNPs exclusively shared between the European taurine Holstein and WAS taurine N'Dama, Kapsiki and Namchi, apart from 162,940 SNPs which were shared between N'Dama and Kapsiki only. 151,865 SNPs and 163,784 SNPs were shared between Cameroonian taurine (Kapsiki and Namchi) and Zebu (Red Fulani, Gudali 


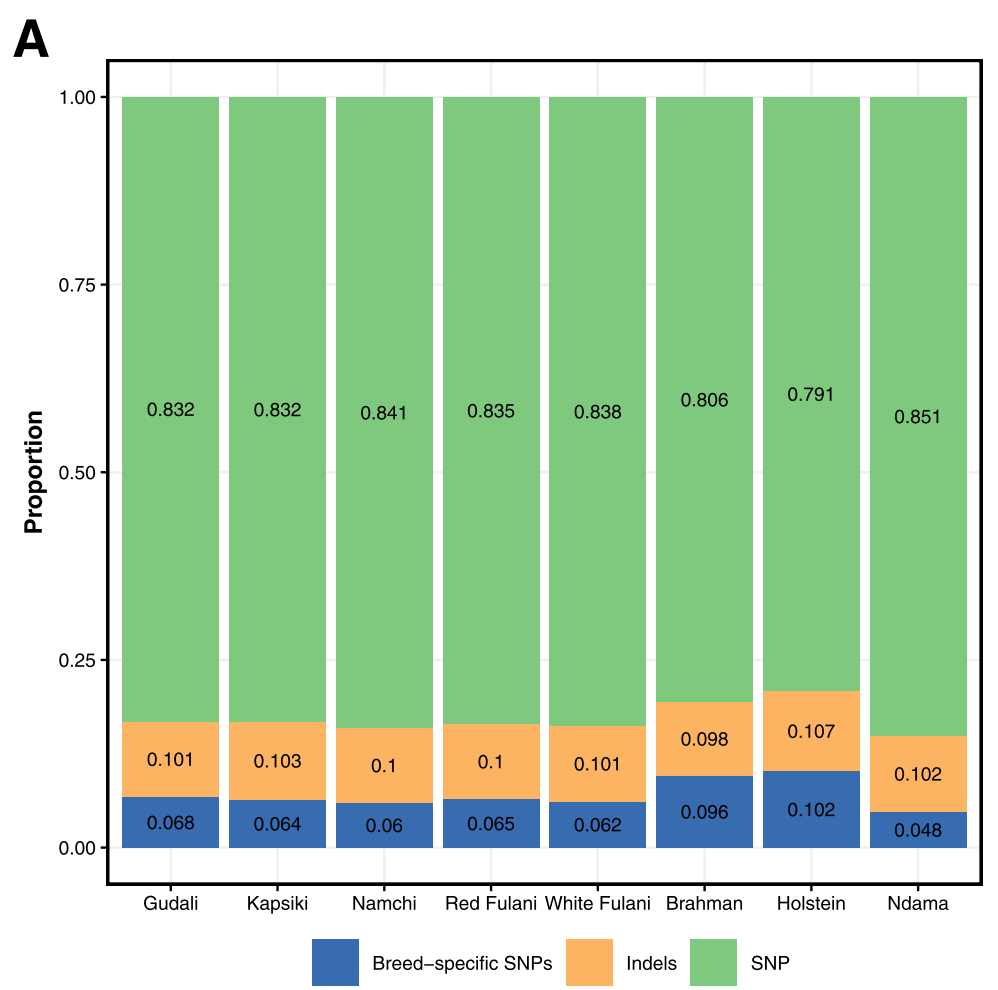

B

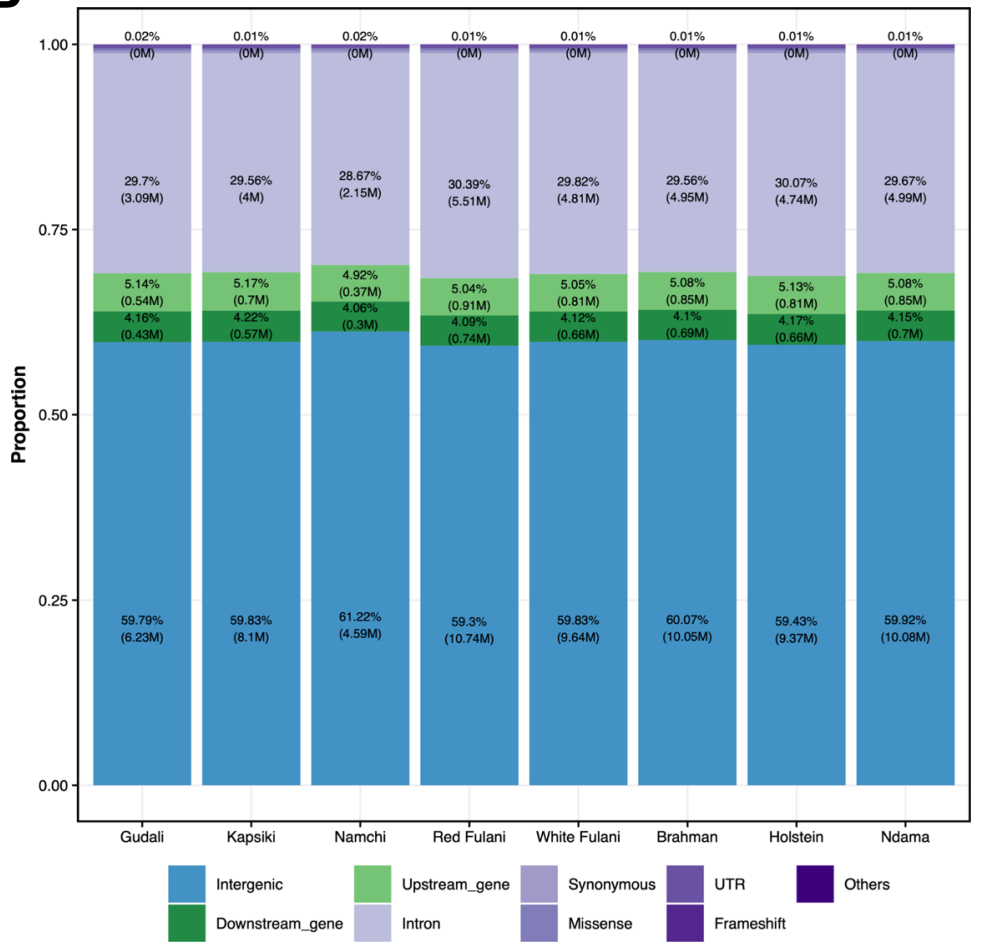

Fig. 2 Distribution of variants per breed and genomic features. A) Bar plot showing the proportion of common SNPs found in at least two breeds (green), breed-specific SNPs (blue) and InDels (orange) across all the examined breeds. B) Bar plot showing numbers in million and proportion of variants types and functional consequences 


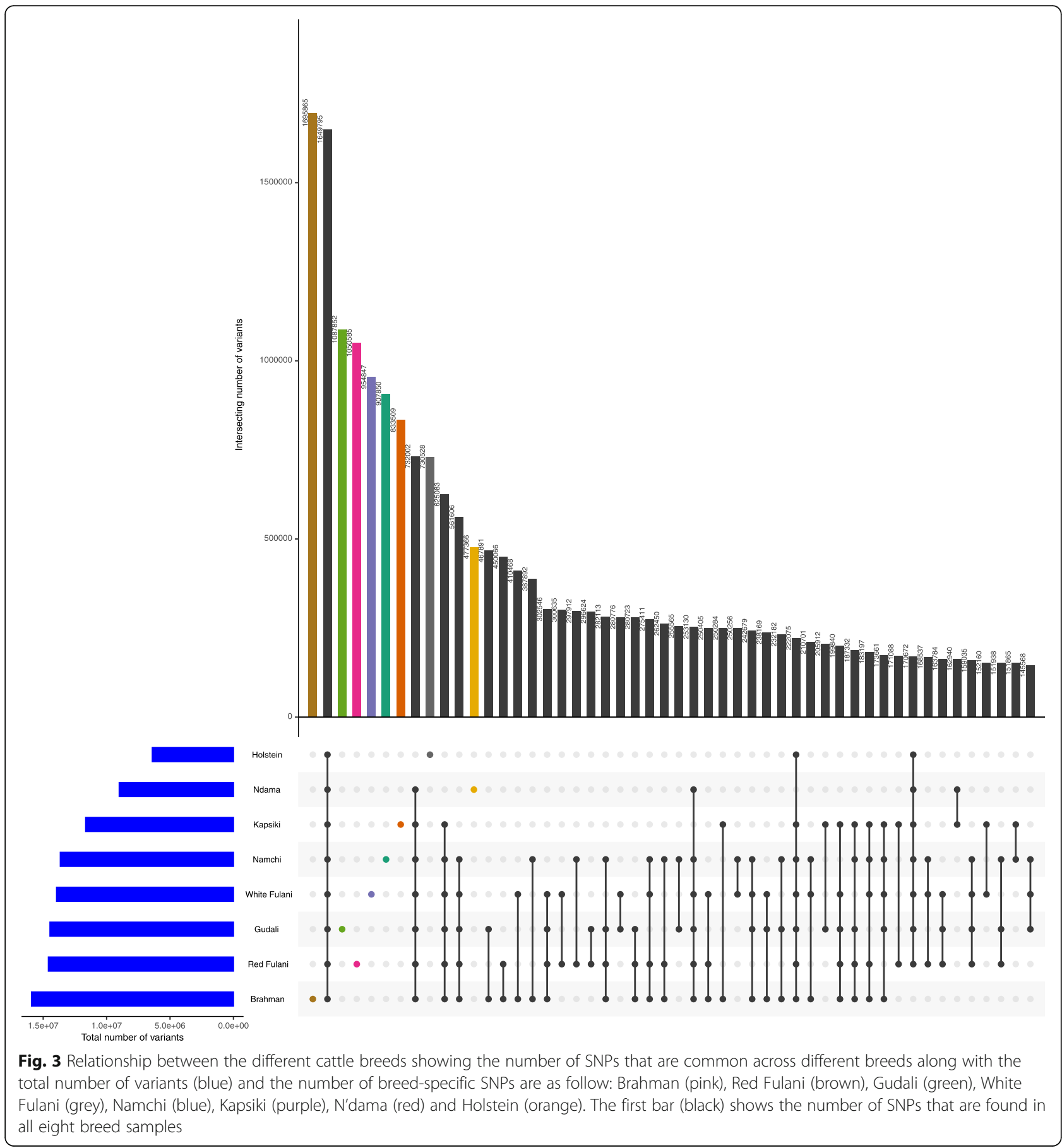

and White Fulani), respectively. Furthermore, 170,672 SNPs were common between all tested cattle breeds except Brahman cattle.

In general, we observed a lower genetic diversity in African taurine cattle breeds than in the Cameroonian Bos indicus breeds (Table 2). The highest proportion of breed-specific (bs) SNPs were found in Bos indicus: Brahman, Red Fulani, Gudali and White Fulani, respectively, and the lowest breed-specific SNPs were found on taurine breeds N'dama, Holstein, Kapsiki and Namchi, respectively (bs-SNPs are color labelled in Fig. 3). This apparently lower genetic diversity in African taurine breeds was already earlier argued by Kim et al. [17] who linked it to the low effective population size and/or population bottlenecks following fatal disease outbreaks such as Rinderpest. In contrast, indicine Zebu cattle and composites with larger effective population size exhibit a higher level of nucleotide diversity. Furthermore, the 
higher nucleotide diversity of taurine Namchi and Kapsiki as compared to N'Dama and Holstein may be due to the long history of Bos indicus introgression [24, 25].

The density of variants per chromosome was proportional to the chromosome length, except for the X chromosomes which showed a lower number of variants identified (Additional file 2 Fig. S2). These findings were expected because the DNA of X chromosomes is subject to an increased natural selection, which leads to less genetic diversity [23].

\section{Breed clustering and relationships}

The cluster relationship between breeds was analyzed by a principal component analysis (PCA) using all autosomal SNPs (Fig. 4A). The first two principal components explain 22 and $16 \%$ of the total variance, respectively. Except for Namchi, the other WAS breeds N'Dama, and Kapsiki form a separate cluster from WAZ breeds. The WAS breeds N'dama, and Kapsiki are also closer to European taurine Holstein than WAZ breeds, and both WAS and WAZ are clearly separated from Zebu Brahman. This indicates the possibility of admixture events between the West African cattle breeds. To further understand the genetic network among those breeds, a phylogenetic tree analysis (Fig. 4B) was carried out with the same autosomal SNPs data as for PCA analysis by using Randomized Accelerated Maximum Likelihood models (RAxML). Again, except for Namchi, the Bos taurus breeds Kapsiki, N'Dama and Holstein cluster together while the B. indicus breeds White Fulani, Gudali, Brahman clustered on a separate clade. The WAS Kapsiki and Namchi cattle are closer to WAZ cattle as compared to European taurine Holstein. In addition, the WAZ are evolutionary distant to Indian Zebu Brahman. This observation concords with previous studies of WAS indicating they possess admixture with indicine ancestry between 22.7 and $74.1 \%$ in Central Africa [26, 27]. Gudali are more closely related to Indian Brahman cattle than White Fulani and Red Fulani (Fig. 4B). The Indian Zebu genes introgression into African Zebu breeds has been reported based on autosomal microsatellite markers between 55 and 83\% [3, 27]. The PCA and RAxML findings presented here illustrate the evolution of Cameroonian cattle breeds is distant both to Indian Zebu Brahman and European taurine Holstein. The higher number of heterozygous to homozygous variants ratio in Kapsiki (2.5) than in Namchi (1.5) (Tables 1 \& 2) was unexpected, because Kapsiki has been regarded as an indigenous taurine population with highest Zebu gene introgression over the last three decades based on microsatellite data [11, 24, 25]. Namchi and Kapsiki have been classified by Freeman et al. [24] as hybrids rather than pure breeds. The phylogenetic position of Namchi more closely related to Red Fulani than WAS indicated recent Zebu introgression into the genome of Namchi. Although the selected Namchi was not different in appearance to other animals in the region, we cannot exclude whether it has been a product of a recent crosshybridization with another cattle breed, and thus not representing the pure breed genome. It is reported that there are still some isolated herds of purebred Namchi cattle in the Poli area, but the present study did not have the tools to screen hybridization levels in the selected animal for whole genome data generation. Such screening would be necessary in the present context where traditional farming systems face numerous challenges towards maintaining purely taurine breeds due to rampant cross breeding.

Functional annotation and gene ontology analysis of high and moderate impact breed-specific SNPs and InDels

The SNPs and InDels were annotated in order to identify the location of the variant in terms of genomic features using the tool snpEFF [28]. In general, all the eight breeds exhibited similar distributions of SNPs and InDels in various genomic annotation categories. Most annotated variants were located in intergenic regions (60\%) and introns (30\%). The remaining SNPs were found on downstream genes (4\%), upstream genes (5\%), untranslated regions (UTR) (0.5\%), missense (0.6\%), frameshift (0.02\%) and other areas (0.7\%) (Fig. 2B).

Breed-specific variants with high and moderate impact such as frameshift, missense, splice acceptor, splice donor, start lost and stop gained, that may putatively change amino-acids codons are located in and/or close to genes that may lead to functional changes were examined in each chromosome. Overall, 4349 genes with such mutations were identified: Most of them were from the breeds White Fulani and Kapsiki (both $>2000$ genes) and the remaining genes were separated on the other breeds as follows: in Red Fulani 11 genes, in Gudali 8 genes, in Namchi 6 genes, and in the three control samples Brahman 27 genes, Holstein 11 genes, and in N'Dama 10 genes, respectively (Additional file 3 Table S3-S10).

These genes were then used to perform a Gene ontology (GO) enrichment analysis for each breed separately. Fifty-two significantly enriched GO terms were identified (Fig. 5) with most significantly enriched terms derived from Kapsiki and White Fulani. Those breeds showed the highest number of genes with bs-SNPs and bsInDels of high and moderate impact. Interestingly, we found enrichment of GO terms related to adaption to high-altitude environment and heat tolerance in Kapsiki, namely the GO terms "peptidase activity" and "scavenger receptor activity". In Namchi, although such GO terms were not significantly enriched, genes such as ADAMTSL1, an ADAMTS like gene, OR9G1, an olfactory receptor (OR) and the surfactant protein $S F T P D$ 


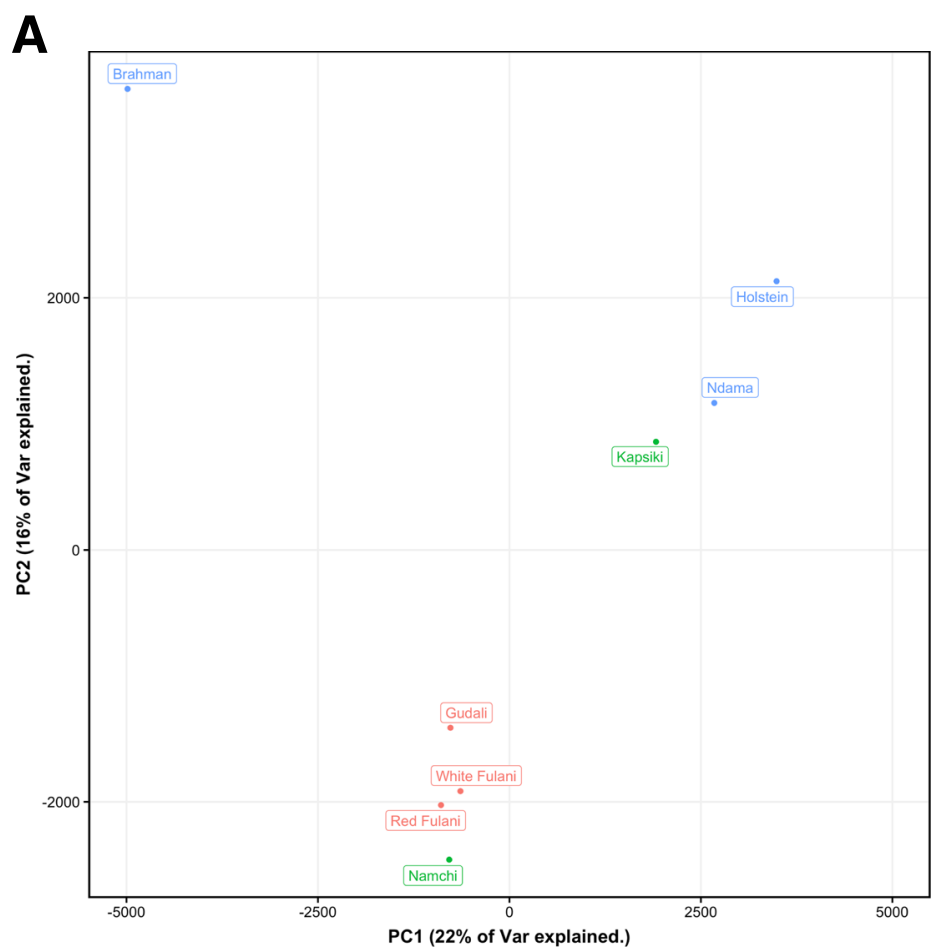

B

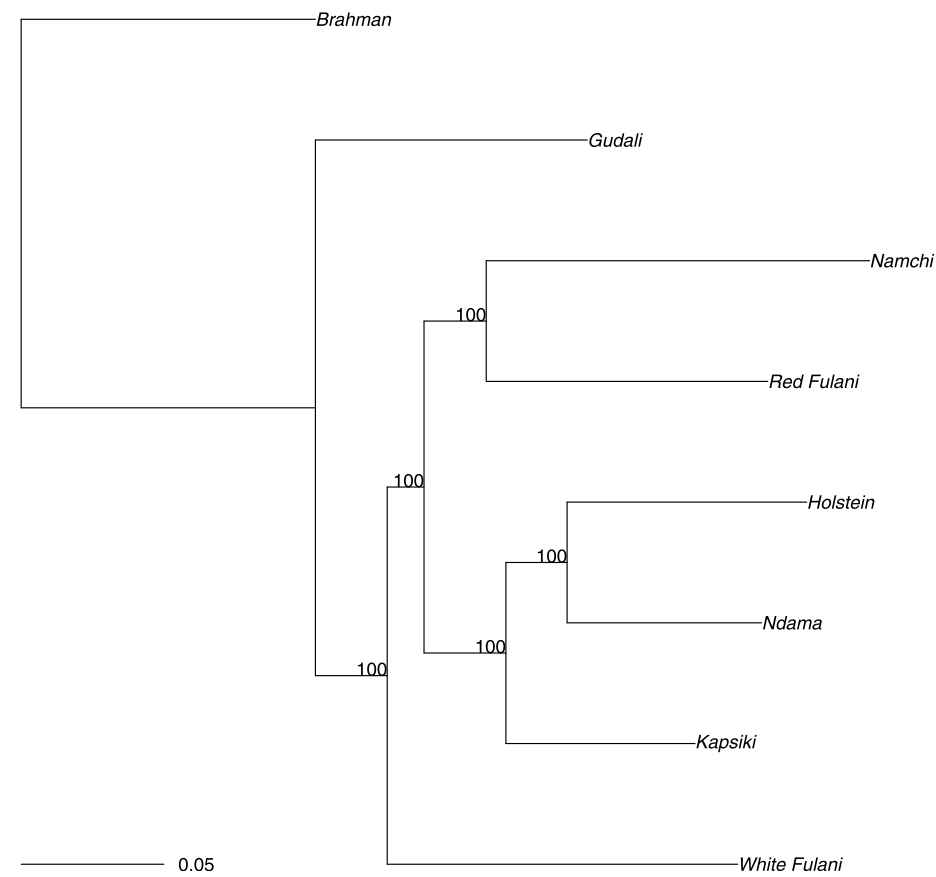

Fig. 4 Genomic relationship among cattle breeds. A) Principal component analysis using autosomal SNP data only, which shows the distribution of different cattle breeds across the first two principal components. Colors separate the samples into the groups Zebu breeds (red), taurine breeds (green) and the three controls (blue) used in this study. B) Phylogenetic maximum likelihood tree of autosomal SNPs variants

were identified carrying either missense variants or frameshift variants (Additional file 3 Table S3). These genes are often reported in the context of heat stress via their interaction with heat shock proteins, but have been also often reported in the context of wound healing [29, 30]. This would imply some genes that contribute to 


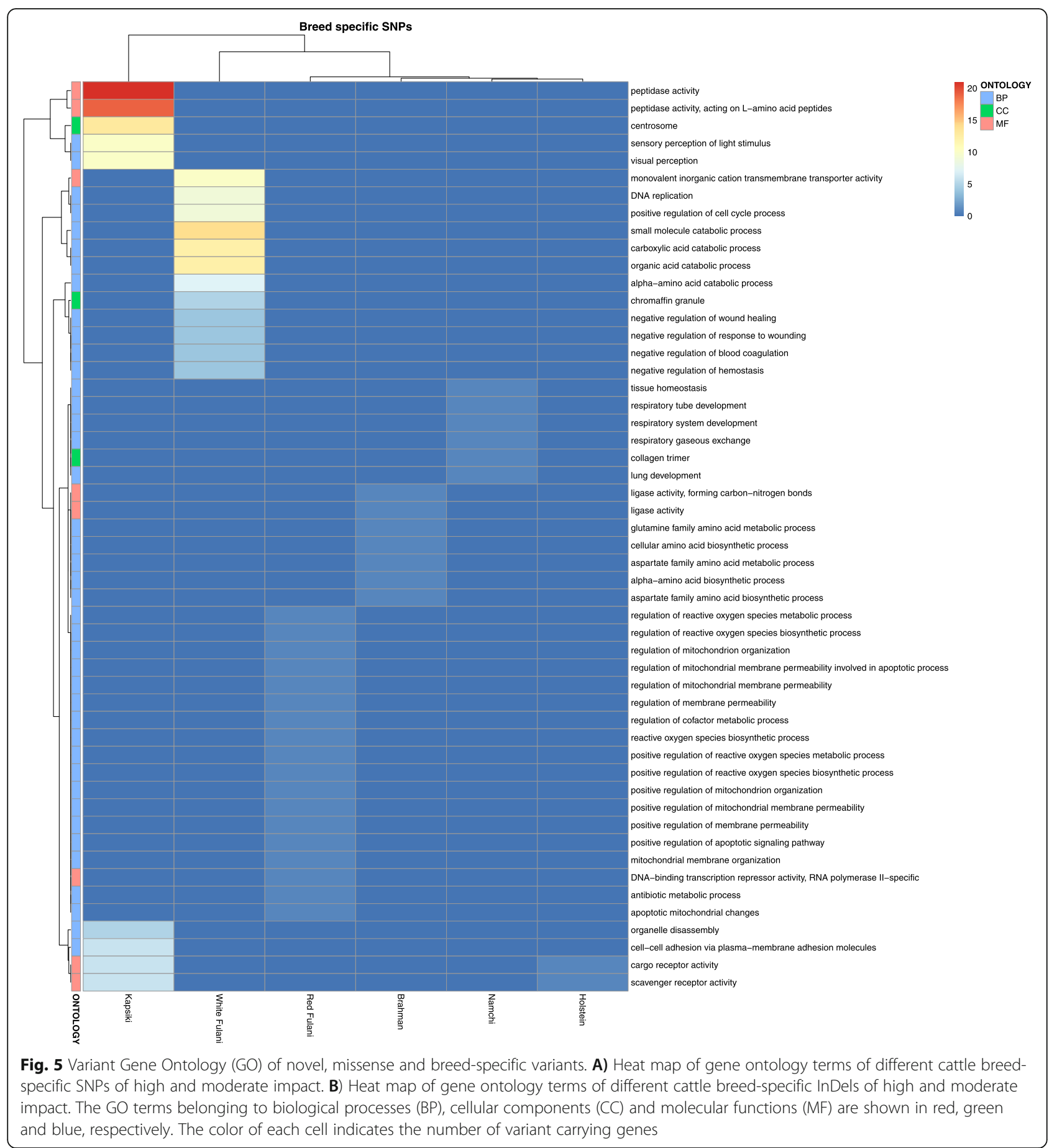

important resistance traits are passed onto hybrid offspring in the Namchi, and might therefore be interesting candidates for further research on increasing trypanotolerance in WAS. In contrast, several enriched GO terms were found in the trypano-susceptible African zebu cattle White and Red Fulani which were absent in the taurine breeds Kapsiki and Namchi. Those GO terms were linked to a negative regulation of wounding or wound healing (Fig. 5, for White Fulani) and a positive regulation of the mitochondria and reactive oxygen species (ROS) metabolic processes (Fig. 5, for Red Fulani). Mitochondria are an important source of ROS within most mammalian cells. They are also generated at wound sites, and act as long-range signals in wound healing. Hence, controlling genes associated with these GO terms might play a vital role in the adaptation to 
infectious diseases in Zebu cattle breeds. In Gudali, another trypanosusceptible African zebu cattle breed, no enriched GO terms were found for SNPs and InDels (Fig. 5). However, several missense variants of high impact were found on an Interferon-inducible GTPase gene (Additional file 3 Table S7). These GTPases provide host resistance to a variety of viral, bacterial and protozoan pathogens through the sequestration of microbial proteins, manipulation of vesicle trafficking, regulation of antimicrobial autophagy [29, 30], which are all congruent for a significant role in the adaptation to infectious diseases.

Taken together, the functional annotation and Gene Ontology analysis identified breed-specific high and moderate impact variants as genetic traits which could help explaining cattle-breed specific phenotypes, such as heat tolerance in Kapsiki and trypanotolerance in Namchi.

\section{Adaptation to tropical climate and high altitude}

Adaptation to local environment is multifactorial involving several genes [1-3]. To cope with heat, poor food and high altitude, African cattle have developed behavioral, cellular and physiological responses to mechanical stress, oxygen, food deprivation and homeostasis [31]. During the evolution of Zebu cattle, they have acquired genes for heat-tolerance at the physiological and cellular levels [32]. The superior ability for regulation of body temperature during heat stress is the result of lower metabolic rates as well as increased capacity of heat tolerance. Heat stress also leads to lightening of the coat, because light colored hair coats have a sleek and shiny reflection [32]. However, the lower metabolic rates under heat stress condition are related to reduction in feed intake, milk yield, thyroid hormone secretion, and growth. This finding may explain the lower performance of meat growth in African Zebu cattle as compared to taurine breeds of European descent. Among many other genes involved in heat stress, four heat shock factor (HSF) genes (HSF1, HSF2, HSF3, and HSF4) have been isolated in vertebrates. HSF1, which is located on chromosome 14, is a master regulator of Heat Shock Protein (HSP70) expression during heat shock [33]. Its interaction with the heat shock proteins HSPA1A/ HSP70 or DNAJB1 result in the inhibition of heat shockand HSF1-induced transcriptional activity during the attenuation and recovery phase from heat shock [34, 35]. European taurine Holstein, WAS, WAZ and Indian Zebu Brahman cattle possess distinct patterns of homozygosity and heterozygosity for the SNP alleles of HSF1. The heterozygosity alleles in these genes were overrepresented in WAS and WAZ as compared to Brahman and Holstein. The increased heterozygosity among the African cattle breeds (WAS and WAZ) indicates the combined effects of genetic isolation and long selection history. In addition, when looking at high and moderate impact bs-SNPs only, in the trypanosusceptible breeds Kapsiki (WAS) and White Fulani (WAZ), but not in the trypanotolerant Namchi and N'Dama, mutations in heat shock proteins were found. The observation that some trypanosusceptible Zebu breeds such as White Fulani carry many mutations in heat shock protein encoding genes [see Additional file 3 Table S6] while other trypanosusceptible Zebu breeds such as Red Fulani and Gudali do not carry any mutations in heat shock proteins, could be further investigated in future genomics research of African cattle breeds towards improving heat stress resistance of those cattle breeds.

\section{Adaptation to pathogens}

Stress response, olfactory receptors and immune responses play a critical role in adaptation to the tropical environment and diseases [17, 25]. Mammalian olfactory receptors (Ors) are encoded by the largest mammalian multigene family with more than 1000 genes organized in clusters on 26 cattle chromosomes [36]. They are essential for avoiding danger, food search, reproduction, and behaviour [36]. Ors have been linked to heat stress but were also reported to accelerate wound healing [29, 37-39], where chemokines play a critical role by enabling the phagocytic leukocytes of the immune system to be the first line of defense against infectious agents, such as protozoa and helminth parasites [30]. The tolerance of Namchi cattle against trypanosomiasis (trypanotolerance) caused by the protozoan parasites Trypanosoma congolense, T. vivax and T. brucei is actively driven by the innate immune response. IL-12, INF- $\gamma$ and TNF- $\alpha$ are primarily produced by cells of the innate immune system and trigger phagocytic cell activation and inflammation, thus contributing to the control of parasite growth [40]. Sialic acid binding immunoglobulin-like lectin (SIGLEC) and the major histocompatibility complex $(\mathrm{MHC})$ gene family, also known in cattle as bovine leukocyte antigens (BoLA) genes, are key players involved in the regulation of chemokines and cells of innate and adaptive immune responses. SIGLECs are expressed on various white blood cells of the immune system and are involved in the regulation of innate and adaptive immunity [41]. In contrast, studies have also shown that many coated sialylated viruses, bacteria and parasites are capable to mimic self-recognition and thus dampen or evade an immune response [41].

Genetic polymorphisms in the mentioned genes have been often linked to wounding processes and pathogen resistance. For instance, polymorphisms in BOLA-DRB3 and other BoLA genes were linked to resistance against viral, bacterial and other parasite infections [42-45]. In this study, 6 high and moderate impact variants such as 
frameshift or missense variants were detected in BoLA genes in Kapsiki, and 9 were found in White Fulani. Furthermore, high and moderate impact variants were found in Namchi, located in Ors such as the previously mentioned OR9G1 gene and in the SIGLEC-1 gene in Kapsiki (Additional file 3, Table S3 and S5). In addition, a different level of polymorphisms in the genomic region of the BoLA genes on chromosome 23 of the cattle reference genome was observed for all breeds analyzed (Additional file 4, Fig. S11). The trypanosusceptible cattle Kapsiki carried the highest number of homozygous and heterozygous alleles in this region while the other studied trypanotolerant cattle breeds such as Namchi and N'Dama showed a lower level of polymorphism, especially in the BOLA-DYB and BOLA-DOB regions (Additional file 4, Fig. S11). However, the results obtained here for Namchi could also be due to previously mentioned possible hybrid status of the selected animal with a recent introgression of Zebu genes into its genome.

The findings provide the first comprehensive set of genome-wide high quality sequencing and variant data of the most important Cameroonian cattle breeds. Although this study was conducted on single samples per breed only, which does not allow us to correctly separate within from across breed variation, we think that the obtained high quality genomic data shall constitute a foundation for breed amelioration whilst exploiting the heritable traits and support conservation efforts for the endangered local cattle breeds.

\section{Conclusions}

The whole genome of five indigenous Cameroonian cattle Namchi, Kapsiki, Gudali, White Fulani and Red Fulani was sequenced and analyzed for the first time, and variant calling results were compared to the reference genomes of European Bos taurus Holstein, African Bos taurus N'Dama and one Asian Zebu Bos indicus Brahman. The findings obtained in this study indicated that both Namchi and Kapsiki cattle possess genotypes and phenotypes associated with disease susceptibility or resistance and heat tolerance, which are complex mechanisms involving several gene pathways located on different chromosomes. This is in line with previous findings, and therefore the high impact variants found in this study could provide potential markers for future genome-wide association studies (GWAS). All the candidate genes could hence constitute a valuable resource for development and genetic amelioration of tropical cattle breeds, particularly in Africa. Furthermore, the full high depth sequence data widens our knowledge on the value of native breeds as genetic resources for future cattle breeding, and the power of selection signature analyses.

\section{Methods}

\section{Sampling, library construction and sequencing}

The data used for this paper was obtained from the project "Pathogen detection in African cattle Breeds" Abanda et al. [18] and Paguem et al. [19].

One representative individual of each of the five different cattle breeds was selected (Table 3).

Blood samples of $5 \mathrm{ml}$ volume per animal were collected in ethylene diamine tetra acetic acid (EDTA)coated vacutainers during the routine examination. The blood was centrifuged at $3000 \mathrm{rpm}$ for $15 \mathrm{~min}$. Then, genomic DNA was extracted from the buffy coat (cellular layer including leucocytes, erythrocytes and blooddwelling parasites like Anaplasmataceae bacteria, piroplasmids, microfilariae of Setaria, trypanosomes and Borrelia spp. (see Additional file 5 Table S12 for trypanosome, Onchocerca filarial and gastrointestinal parasites detected on those animals) using the Wizard Genomic DNA Purification Kit (Promega, Germany) according to the manufacturer's instructions. DNA isolation and concentration was verified by fluorescent methods using Picogreen (Life Technologies). Libraries were generated from $2 \mu \mathrm{g}$ of genomic DNA per specimen using the Illumina TruSeq DNA PCR-Free Library Prep Kit (Illumina, San Diego, CA, USA) following the manufacturer's protocol. $2 \times 150 \mathrm{bp}$ paired-end libraries sequencing was conducted on the Illumina HiSeq4000 platform with the manufacturer's proprietary TruSeq SBS Kit V3-HS.

Table 3 Information of the selected animals of Cameroonian cattle breeds for whole genome re-sequencing

\begin{tabular}{|c|c|c|c|c|c|c|c|c|c|}
\hline \multirow[t]{2}{*}{ Breed } & \multirow{2}{*}{$\begin{array}{l}\text { Age } \\
\text { [years] }\end{array}$} & \multirow[t]{2}{*}{ Sex } & \multicolumn{2}{|l|}{ Sampling sites } & \multicolumn{2}{|c|}{ GPS Coodinates } & \multirow[t]{2}{*}{ Altitude } & \multirow{2}{*}{$\begin{array}{l}\text { LW } \\
{[\mathrm{kg}]}\end{array}$} & \multirow[t]{2}{*}{ Subspecies } \\
\hline & & & Region & Village & $\mathrm{N}$ & $E$ & & & \\
\hline Namchi & 6 & male & Faro & Herko & $8^{\circ} 30^{\prime} 05.1^{\prime \prime}$ & $13^{\circ} 08^{\prime} 28.7^{\prime \prime}$ & $520 \mathrm{~m}$ & 252 & Bos taurus brachyceros \\
\hline \multicolumn{10}{|l|}{ (Doayo) } \\
\hline Kapsiki & 5 & female & Mayo-Tsanaga & Rhumsiki/Kila & $10^{\circ} 27^{\prime} 45.5^{\prime \prime}$ & $13^{\circ} 38^{\prime} 22.9^{\prime \prime}$ & $956 \mathrm{~m}$ & 252 & Bos taurus brachyceros \\
\hline W. Fulani & 5 & female & Mayo-Rey & Bini & $07^{\circ} 37^{\prime} 29.6^{\prime \prime}$ & $14^{\circ} 32^{\prime} 10.1^{\prime \prime}$ & $780 \mathrm{~m}$ & 240 & Bos indicus indicus \\
\hline R. Fulani & 5 & female & Mayo-Rey & Bini & $07^{\circ} 37^{\prime} 29.6^{\prime \prime}$ & $14^{\circ} 32^{\prime} 10.1^{\prime \prime}$ & $780 \mathrm{~m}$ & 313 & Bos indicus indicus \\
\hline Gudali & 7 & female & Vina & Galim & $07^{\circ} 12^{\prime} 2.39^{\prime \prime}$ & $13^{\circ} 34^{\prime} 49.70^{\prime \prime}$ & $1050 \mathrm{~m}$ & 400 & Bos indicus indicus \\
\hline
\end{tabular}

W. Fulani White Fulani, R. Fulani Red Fulani, $L W$ Live weight 


\section{Short read mapping, variant calling and annotation}

The quality of the generated raw Illumina reads was determined using Fast QC software (http://www.bioinformatics.bbsrc.ac.uk/projects/fastqc/). Adaptor read sequences were removed using SeqPurge from ngs-bits4 (https:// github.com/imgag/ngs-bits, version 0.1-4-gaed0c94). For comparison with other cattle breeds, whole genome raw sequencing data from NCBI Sequence Read Archive SRA was extracted for the breeds Holstein (SRR934414), N'Dama (SRR3693376) and Brahman (SRR6649996). Paired-end reads from the five samples along with these three controls from the SRA archive were mapped against the reference Bos taurus Hereford breed genome UMD3.1 (NCBI refSeq accession GCA_000003055.5) and ARSUCD1.2 (NCBI RefSeq accession GCF_002263795.1) respectively, using BWA-MEM version 0.7.10-r789 [41]. Reads that mapped to a single location in the genome (uniquely mapped reads) were selected, and those with multiple region mapping were excluded using the MarkDuplicates tool of Picard5 v.1.137 (http://broadinstitute.github.io/picard). After sequence alignment, the resulting SAM files format were converted to BAM files using Samtools v.1.3 [46]. Then BAM files were sorted and local realignment of reads was performed to correct misalignment due to the presence of small InDels using Genome Analysis Tool Kit 3.1 (GTAK). SNPs and InDels calling were performed using Freebayes v.0.9.21-19gc003cle [47]. SNPs and InDels were annotated using snpEFF [28] and Bcftools [46]. To have many of these processes parallelized and automated, a workflow written in the workflow language Snakemake from QbiC was used which is freely available at Github (https:/github.com/ qbicsoftware/exomseq).

The variants that were identified in only one cattle breed and have no corresponding entries in the dbSNP database (for mapping to UMD3.1) or 1000 Bull Genomes Project (for mapping to ARS-UCD1.2) were classified as breed-specific novel variants. The average ratios of homozygous versus heterozygous SNPs were calculated for each breed. This ratio is expected to be 1 : 2 in a freely mating population; therefore, any departure from this condition such as the presence of admixture in the population will be manifested by an increase in the homozygous/heterozygous ratio [48].

\section{Unmapped read analysis}

Reads that were not mapped to the reference genome UMD3.1 and ARS-UCD1.2, respectively, were extracted from alignment BAM files and sorted by name using Samtools. The sorted BAM files were given as input to AbySS (version 2.1.5) and assembled using the parameter " $\mathrm{k}=25$ " indicating $\mathrm{k}$-mer size = 25 in standard de Bruijn graph mode. Resulting contigs.fa files were subdivided into contigs with a length $>500 \mathrm{bp}$. Then the remaining contigs were searched against Blastn database using NucleotideNucleotide BLAST (version 2.8.1+) with the parameters “-num_alignments 1"and "-num_descriptions 1" to show alignments and descriptions for the top 1 matching database match only. The BLAST output was then parsed using the $\mathrm{R}$ language (version 3.4.0) to determine for each sample the species of the BLAST hit, the percent identity, length of match and query, and BLAST e-value. Mean values of these statistics were calculated for each species in each sample.

\section{Gene enrichment and functional analysis}

For downstream analysis of single nucleotide polymorphisms (SNPs) we used the genome ARS-UCD1.2 but not UMD3.1 and compared it with reference genomes of European Bos taurus Holstein, Asian Bos indicus Brahman and African trypanotolerant N'Dama breeds. Breed-specific non-synonymous (bs-ns) SNPs, InDels with moderate and high impact in the genome and new variants not found in any publicly available database were extracted from WAS and WAZ using the data repositories Ensembl release 76, dbSNP138, Entrez Gene, NCBI and Uniprot. The variant carrying genes were functionally characterized based on different gene ontology (GO) terms using clusterProfiler (v3.12) R package(v3.5.2) [49].

\section{Phylogeny of bovine-related species}

To understand the genetic relationships between indigenous cattle breeds and other subfamilies of Bovidae, a principal component analysis (PCA) was performed with EIGENSTRAT. For the phylogenetic tree reconstruction, the variant files were converted to FASTA format with Vcf-kit8 (https://vcf-kit.readthedocs.io/en/latest/). Multiple sequence alignment (MSA) was generated using Muscle with default options [50]. Prottest3 [51] was used to find the best substitution model for the MSA, and RAxML was used to generate the Maximum Likelihood (ML) tree with Blossum62 as best substitution model along with Gamma distribution for rate heterogeneity, estimation for proportion of invariable sites and 100 non-parametric bootstrap replicates using Brahman as outgroup [52]. Visualization of the tree was generated using ape (v5.3) R package [53].

\section{Supplementary information}

Supplementary information accompanies this paper at https://doi.org/10. 1186/s12863-020-00869-9.

Additional file 1: Table S1. Pairwise alignment of contigs assembled from unmapped reads to the non-redundant nucleotide database. 
Additional file 2: Figure S2. Distribution of SNPs, InDels and breedspecific SNPs per chromosome and breed. Bar plot illustrates the number of SNPs found in at least two breeds (green), breed-specific SNPs (blue) and InDels (orange) across all the breeds for each chromosome.

Additional file 3: Table S3. High impact Namchi breed specific SNP. Table S4. High impact Kapsiki breed specific SNP. Table S5. High impact Red Fulani breed specific SNP. Table S6. High impact White Fulani breed specific SNP. Table S7. High impact Gudali breed specific SNP. Table S8. High impact Brahman breed specific SNP. Table S9. High impact Holstein breed specific SNP. Table S10. High impact N'Dama breed specific SNP.

Additional file 4: Figure S11. Distribution of SNPs per cattle breed of chromosome 23 between location 25,350,340 and 25,593,072 containing the BoLA gene. The $X$ axis represents genomic location and $y$-axis represents ratio of non-reference base. Value 1 indicates that all reads carry the non-reference base at a given location whereas a value of 0.5 and 0 indicates half and none of the reads carry the non-reference base, respectively.

Additional file 5: Table S12. Trypanosome, Onchocerca filarial and gastro-intestinal parasites detected from five animals of each cattle breed detected by microscopy and molecular diagnostics using ribosomal nuclear makers.

\section{Abbreviations}

GO: Gene ontology; PCA: Principal component analysis; WAS: West African Shorthorn; WAZ: West African Zebu; bs-ns: Breed-specific non-synonymous; HSPA: Heat Shock 70 Kda protein; HSF: Heat shock factor; Ors: Olfactory receptors; BoLA: Bovine leucocyte antigen; SNPs: Single nucleotide polymorphism variants; InDels: Insertions and Deletions variants; Gb: Giga base pairs

\section{Acknowledgements}

The authors are indebted to Drs. Madi Palou and Manchang Kingsley from the Wakwa Centre of the Institute of Agricultural Research for Development, and the research staff of the Programme Onchocercoses field station of the University of Tübingen in Ngaoundéré for logistical support and assistance during the fieldwork, and Dr. Fernanda Ruiz-Fadel from the University of Tübingen for proof reading the manuscript.

\section{Authors' contributions}

Conceptualization: AE, MDA, AR, SC. Formal analysis: AP, PB, SC. Investigation: $A P, B A, M D A$. Project administration: AE. Resources: AE, AP, AR. Supervision: $A R, A E, M D A$. Writing, review and editing: AP, BA, MDA, AR, PB, SC, AE. All authors read and approved the final manuscript.

\section{Funding}

Research grants from the Otto Bayer Foundation (F-2013BS522), International Foundation for Science (IFS); Stockholm, Sweden (B/5864-1) and German Research Foundation (DFG, grant no. RE 1536/2) funded the fieldwork data used for this paper from the project "Pathogen detection in African cattle breeds" [Paguem et al., 2019; Abanda et al., 2019], whereas the full genome sequences of five cattle breeds and bioinformatics analysis was funded by the joint RiSC program of the State Ministry of Science, Research and Arts Baden-Württemberg and the University of Tübingen (PSP-no. 4041002616). We acknowledge support by Open Access Publishing Fund of University of Tübingen.

\section{Availability of data and materials}

All data generated or analyzed during this study are included in this published article, and its additional information files are available from the corresponding author on reasonable request. The five newly sequenced African cattle genomes in this study are publicly available from GenBank with the Bio project SRA accession: PRJNA596606).

\section{Ethics approval and consent to participate}

Permission for the study and ethical approval were obtained from the Scientific Directorate of the Institute of Agricultural Research for Development (IRAD) in Cameroon, which is the country's government research institution for animal health and livestock husbandry improvement. Furthermore, verbal consent was given by the cattle owners and herdsmen.

\section{Consent for publication}

Not applicable.

\section{Competing interests}

The authors declare that they have no competing interests.

\section{Author details}

${ }^{1}$ Department of Biological Science, Faculty of Science, University of Ngaoundéré, Ngaoundéré, Cameroon. ²Department of Comparative Zoology, Institute for Evolution and Ecology, University of Tübingen, Tübingen, Germany. ${ }^{3}$ TOZARD Research Laboratory, P.O. Box 59, Bambili-Tubah, Bamenda, Cameroon. ${ }^{4}$ Quantitative Biology Center (QBiC), University of Tübingen, Tübingen, Germany. ${ }^{5}$ Institute of Novel and Emerging Infectious Diseases, Friedrich-Loeffler-Institut, Federal Research Institute for Animal Health, Insel Riems, Greifswald, Germany.

\section{Received: 20 December 2019 Accepted: 9 June 2020}

Published online: 22 June 2020

\section{References}

1. Mwai $\mathrm{O}$, Hanotte $\mathrm{O}$, Kwon YJ, Cho S. African indigenous cattle: unique genetic resources in a rapidly changing world. Asian-Australas J Anim Sci. 2015;28(7):911-21.

2. Rege J, Hanotte $O$, Mamo Y, Asrat B, Dessie T. Domestic animal genetic resources information system (DAGRIS) Addis Ababa: International Livestock Research Institute; 2007.

3. Hanotte O, Bradley DG, Ochieng JW, Verjee Y, Hill EW, Rege JE. African pastoralism: genetic imprints of origins and migrations. Science. 2002; 296(5566):336-9.

4. Achukwi MD, Tanya VN, Messine O, Njongmeta LM. Etude comparative de l'infestation des bovins Namchi (Bos taurus) et Goudali de Ngaoundere (Bos indicus) par des tiques adultes Amblyomma variegatum. Rev Elev Méd Vét Pays Trop. 2001;54(1):37-41.

5. Awa DN, Achukwi MD. Livestock pathology in the central African region: some epidemiological considerations and control strategies. Anim Health Res Rev. 2010;11(2):235-44.

6. Epstein $\mathrm{H}$. The origin of the domestic animals of Africa. New York, NY; London. Munich: Africana Publishing Corporation; 1971.

7. Loftus RT, Ertugrul O, Harba AH, El-Barody MA, MacHugh DE, Park SD, Bradley DG. A microsatellite survey of cattle from a Centre of origin: the near east. Mol Ecol. 1999;8(12):2015-22.

8. Achukwi MD, Ibeagha-Awemu EM, Musongong GA, Erhardt G. Doayo (Namchi) Bos taurus cattle with low zebu attributes are trypanotolerant under natural vector challenge. Online J Vet Res. 2009;13(1):94-105.

9. Dineur B, Thys E. Les Kapsiki: race taurine de l'extrême nord camerounais. I. Introduction et barymétrie. Rev Elev Méd Vét Pays Trop. 1986;39(3-4):435-42

10. FAO. The management of global animal genetic resources. Rome: Anim Prod Health; 1992

11. Achukwi MD, Tanya VN, Hill EW, Bradley DG, Meghen C, Sauveroche B, Banser JT, Ndoki JN. Susceptibility of the Namchi and Kapsiki cattle of Cameroon to trypanosome infection. Trop Anim Health Prod. 1997;29(4): 219-26.

12. Tawah CL, Rege JEO: Gudali cattle of West and Central Africa. In: Anim Gen Res Info. Rome, Italy: FAO: 1994

13. Tawah $\mathrm{CL}$, Rege J. White Fulani cattle of west and Central Africa. Anim Gen Res Info. 1996:17:127-45.

14. Fréchou H: L'élevage et le commerce du bétail dans le nord du Cameroun. In Série Sciences Humaines. Edited by ORSTOM Cdl. Cahiers d'outre-mer. Bordeaux: Ateliers de I'Union Française d'Impression; 1966:319-320.

15. Bradley DG, MacHugh DE, Cunningham P, Loftus RT. Mitochondrial diversity and the origins of African and European cattle. Proc Natl Acad Sci U S A. 1996;93(10):5131-5.

16. Taye M, Lee W, Caetano-Anolles K, Dessie T, Hanotte O, Mwai OA, Kemp S, Cho S, Oh SJ, Lee HK, et al. Whole genome detection of signature of positive selection in African cattle reveals selection for thermotolerance. Anim Sci J. 2017;88(12):1889-901. 
17. Kim J, Hanotte O, Mwai OA, Dessie T, Bashir S, Diallo B, Agaba M, Kim K, Kwak W, Sung $S$, et al. The genome landscape of indigenous African cattle. Genome Biol. 2017;18(1):34.

18. Abanda B, Paguem A, Mamoudou A, Manchang TK, Renz A, Eisenbarth A. Molecular identification and prevalence of tick-borne pathogens in zebu and taurine cattle in North Cameroon. Parasite Vectors. 2019:12:448.

19. Paguem A, Abanda B, Ndjonka D, Weber JS, Ngomtcho SCH, Manchang TK, Mamoudou A, Eisenbarth A, Renz A, Kelm S, Achukwi MD. Widespread co-endemic occurrence of Trypanosoma species infecting cattle in the Sahel and Guinea Savannah zones of Cameroon. BMC Vet Research. 2019;15:344

20. Rosen DB., Bickhart MD., Schnabel DR, Koren S, Elsik GC, Tseng E, Rowan NT, Low YW, Zimin A, Couldrey C., et al: De novo assembly of the cattle reference genome with single-molecule sequencing. Giga Science 2020, 9:3. doi.org/10.1093/gigascience/giaa021.

21. Kawahara-Miki R, Tsuda K, Shiwa Y, Arai-Kichise $Y$, Matsumoto T, Kanesaki Y, Oda S, Ebihara S, Yajima S, Yoshikawa H, et al. Whole-genome resequencing shows numerous genes with nonsynonymous SNPs in the Japanese native cattle Kuchinoshima-Ushi. BMC Genomics. 2011;12(103):103.

22. Taylor JF, Whitacre LK, Hoff JL, Tizioto PC, Kim J, Decker JE, Schnabel RD. Lessons for livestock genomics from genome and transcriptome sequencing in cattle and other mammals. Genet Sel Evol. 2016;48(1):59.

23. Stafuzza NB, Zerlotini A, Lobo FP, Yamagishi ME, Chud TC, Caetano AR, Munari DP, Garrick DJ, Machado MA, Martins MF, et al. Single nucleotide variants and InDels identified from whole-genome re-sequencing of Guzerat, Gyr, Girolando and Holstein cattle breeds. PLoS One. 2017;12(3): e0173954.

24. Freeman AR, Meghen CM, MacHugh DE, Loftus RT, Achukwi MD, Bado A, Sauveroche B, Bradley DG. Admixture and diversity in west African cattle populations. Mol Ecol. 2004;13(11):3477-87.

25. Bahbahani H, Tijjani A, Mukasa C, Wragg D, Almathen F, Nash O, Akpa GN, Mbole-Kariuki M, Malla S, Woolhouse M, et al. Signatures of selection for environmental adaptation and zebu $\times$ Taurine hybrid fitness in east African shorthorn zebu. Front Genet. 2017;8(68):68.

26. Decker JE, McKay SD, Rolf MM, Kim J, Molina Alcala A, Sonstegard TS, Hanotte O, Gotherstrom A, Seabury CM, Praharani L, et al. Worldwide patterns of ancestry, divergence, and admixture in domesticated cattle. PLoS Genet. 2014;10(3):e1004254.

27. MacHugh DE, Shriver MD, Loftus RT, Cunningham P, Bradley DG. Microsatellite DNA variation and the evolution, domestication and phylogeography of taurine and zebu cattle (Bos taurus and Bos indicus). Genetics. 1997;146(3):1071-86.

28. Cingolani P, Platts A, Wang le L, Coon M, Nguyen T, Wang L, Land SJ, Lu X, Ruden DM: A program for annotating and predicting the effects of single nucleotide polymorphisms, SnpEff: SNPs in the genome of Drosophila melanogaster strain w1118; iso-2; iso-3. Fly (Austin) 2012, 6(2):80-92.

29. Mirastschijski U, Schwab I, Coger V, et al. Lung surfactant accelerates skin wound healing: a translational study with a randomized clinical phase I study. Sci Rep. 2020;10(1):2581.

30. Murdoch C, Finn A. Chemokine receptors and their role in inflammation and infectious diseases. Blood. 2000;95(10):3032-43.

31. Erb L, Weisman GA. Coupling of $P 2 Y$ receptors to $G$ proteins and other signaling pathways. Wiley Interdiscip Rev Membr Transp Signal. 2012;1(6): 789-803.

32. Hansen PJ. Physiological and cellular adaptations of zebu cattle to thermal stress. Anim Reprod Sci. 2004;82-83:349-60.

33. Fujimoto $M$, Nakai $A$. The heat shock factor family and adaptation to proteotoxic stress. FEBS J. 2010;277(20):4112-25.

34. Rabindran SK, Wisniewski J, Li L, Li GC, Wu C. Interaction between heat shock factor and Hsp70 is insufficient to suppress induction of DNA-binding activity in vivo. Mol Cell Biol. 1994;14(10):6552-60.

35. Baler R, Zou J, Voellmy R. Evidence for a role of Hsp70 in the regulation of the heat shock response in mammalian cells. Cell Stress Chaperones. 1996; 1(1):33-9.

36. Lee K, Nguyen DT, Choi M, Cha SY, Kim JH, Dadi H, Seo HG, Seo K, Chun T, Park C. Analysis of cattle olfactory subgenome: the first detail study on the characteristics of the complete olfactory receptor repertoire of a ruminant. BMC Genomics. 2013:14:596.

37. Kelwick R, Desanlis I, Wheeler GN, Edwards DR. The ADAMTS (a Disintegrin and metalloproteinase with Thrombospondin motifs) family. Genome Biol. 2015;16(1):113.
38. Neuhaus EM, Mashukova A, Zhang W, Barbour J, Hatt H. A specific heat shock protein enhances the expression of mammalian olfactory receptor proteins. Chem Senses. 2006;31(5):445-52.

39. Busse D, Kudella P, Grüning NM, Gisselmann G, Ständer $S$, Luger T, Jacobsen F, Steinsträßer L, Paus R, Gkogkolou P, et al. A synthetic sandalwood odorant induces wound-healing processes in human keratinocytes via the olfactory receptor OR2AT4. J Invest Dermatol. 2014;134(11):2823-32.

40. Abrahamsohn IA. Cytokines in innate and acquired immunity to Trypanosoma cruzi infection. Braz J Med Biol Res. 1998;31(1):117-21.

41. Paulson JC, Macauley MS, Kawasaki N. Siglecs as sensors of self in innate and adaptive immune responses. Ann N Y Acad Sci. 2012;1253:37-48.

42. Takeshima S, Aida Y. Structure, function and disease susceptibility of the bovine major histocompatibility complex. Anim Science J. 2006;77(2):138-50.

43. Takeshima S, Matsumoto Y, Chen J, Yoshida T, Mukoyama H, Aida Y. Evidence for cattle major histocompatibility complex (BoLA) class II DQA1 gene heterozygote advantage against clinical mastitis caused by streptococci and Escherichia species. Tissue Antigens. 2008;72(6):525-31.

44. Untalan PM, Pruett JH, Steelman CD. Association of the bovine leukocyte antigen major histocompatibility complex class II DRB3*4401 allele with host resistance to the lone star tick. Amblyomma americanum Vet Parasitol. 2007;145(1-2):190-5.

45. Xu A, van Eijk MJ, Park C, Lewin HA. Polymorphism in BoLA-DRB3 exon 2 correlates with resistance to persistent lymphocytosis caused by bovine leukemia virus. J Immunol. 1993;151(12):6977-85.

46. Li H, Handsaker B, Wysoker A, Fennell T, Ruan J, Homer N, Marth G, Abecasis G, Durbin R. Genome project data processing S: the sequence alignment/ map format and SAMtools. Bioinformatics. 2009;25(16):2078-9.

47. Garrison E, Marth G: Haplotype-based variant detection from short-read sequencing. arXiv Preprint; 2012. Available from: http://arxiv.org/abs/1207.3907.

48. Scally A, Yngvadottir B, Xue Y, Ayub Q, Durbin R, Tyler-Smith C. A genomewide survey of genetic variation in gorillas using reduced representation sequencing. PLoS One. 2013;8(6):e65066.

49. Yu G, Wang LG, Han Y. He QY: clusterProfiler: an R package for comparing biological themes among gene clusters. OMICS. 2012;16(5):284-7.

50. Edgar RC. MUSCLE: multiple sequence alignment with high accuracy and high throughput. Nucleic Acids Res. 2004;32(5):1792-7.

51. Darriba D, Taboada GL, Doallo R, Posada D. ProtTest 3: fast selection of bestfit models of protein evolution. Bioinformatics. 2011;27(8):1164-5.

52. Stamatakis A. RaxML version 8: a tool for phylogenetic analysis and postanalysis of large phylogenies. Bioinformatics. 2014;30(9):1312-3.

53. Paradis E, Claude J, Strimmer K. APE: analyses of Phylogenetics and evolution in R language. Bioinformatics. 2004;20(2):289-90.

\section{Publisher's Note}

Springer Nature remains neutral with regard to jurisdictional claims in published maps and institutional affiliations.

\section{Ready to submit your research? Choose BMC and benefit from:}

- fast, convenient online submission

- thorough peer review by experienced researchers in your field

- rapid publication on acceptance

- support for research data, including large and complex data types

- gold Open Access which fosters wider collaboration and increased citations

- maximum visibility for your research: over $100 \mathrm{M}$ website views per year

At $\mathrm{BMC}$, research is always in progress.

Learn more biomedcentral.com/submissions 